\title{
Electrocardiographic changes in elderly patients during endoscopic retrograde cholangiopancreatography
}

\author{
NG Kounis MD¹, GM Zavras MD², PJ Papadaki MD², SN Kouni BSc ${ }^{1}, \mathrm{M}^{1}$ Batsolaki PhD ${ }^{1}$, \\ GV Gouvelou-Deligianni SRN ${ }^{1}$, C Markoglou MD², JA Goudevenos MD³ ${ }^{3}$ CN Mallioris MD ${ }^{1}$, \\ C Kokkinis $\mathrm{MD}^{2}$, K Kalokairinou MD², N Grapsas $\mathrm{MD}^{4}$, GN Kounis ${ }^{5}$, CM Koutsojannis PhD ${ }^{1}$
}

\begin{abstract}
NG Kounis, GM Zavras, PJ Papdaki, et al. Electrocardiographic changes in elderly patients during endoscopic retrograde cholangiopancreatography. Can J Gastroenterol 2003;17(9):539-544.
\end{abstract}

BACKGROUND: Cardiorespiratory complications may occur during gastrointestinal endoscopy, and elderly people seem to be more vulnerable to these complications during endoscopic procedures involving the manipulation of abdominal viscera.

OBJECTIVES: To determine the incidence of cardiac arrhythmias, changes in oxygen saturation, heart rate and blood pressure during endoscopic retrograde cholangiopancreatography (ERCP) via Holter monitoring in elderly patients older than 70 years of age.

METHODS: Holter monitoring and 12-lead electrocardiograms were performed in 30 elderly patients undergoing ERCP and in 30 control subjects undergoing routine chest, abdomen, bone and upper gastrointestinal small bowel follow-through studies. A computerized nontriggered template system was used to analyze the electrocardiograms qualitatively and quantitatively. Arrhythmias, cardiac axis, conduction defects, pauses, ST segment changes, ectopic beats, oxygen desaturation and changes in blood pressure and rate-pressure product were evaluated.

RESULTS: Increased heart rate, ST segment changes resulting from myocardial ischemia, oxygen desaturation and transient atrial and ventricular ectopic beats were frequent during ERCP compared with the control group. In one patient, transient left bundle branch block developed and this was attributed to pre-existing hypertension with cardiomegaly. One patient developed ventricular tachycardia and one other sinus bradycardia, but this was attributed to sick sinus syndrome.

CONCLUSIONS: Transient myocardial ischemia and various cardiac arrhythmias are frequent in elderly patients undergoing ERCP. Appropriate noninvasive monitoring seems to be justified during this procedure.

Key Words: Cardiac arrhythmias; Cholangiopancreatography; Elderly; Holter monitoring
Les modifications électrocardiographiques chez les patients âgés pendant une cholangiopancréatographie rétrograde endoscopique

HISTORIQUE : Des complications cardiorespiratoires peuvent se manifester pendant une endoscopie gastro-intestinale, et les personnes âgées semblent plus vulnérables à ces complications pendant les interventions endoscopiques qui entraînent une manipulation des viscères abdominales. OBJECTIFS : Déterminer l'incidence des arythmies cardiaques, les modifications de la saturation en oxygène, le rythme cardiaque et la tension artérielle pendant une cholangiopancréatographie rétrograde endoscopique (CPRE) par la méthode de Holter chez des patients âgés de plus de 70 ans.

MÉTHODOLOGIE : La méthode de Holter et des électrocardiogrammes à 12 dérivations ont été utilisés chez 30 patients âgés subissant une CPRE et chez 30 sujets témoins subissant un bilan systématique du thorax, de l'abdomen, des os et de la partie supérieure de l'intestin grêle. Un système informatisé de matrice non déclenché a permis d'analyser les électrocardiogrammes de manière qualitative et quantitative. Les arythmies, l'axe du cœur, les anomalies de conduction, les pauses, les modifications du segment $\mathrm{ST}$, les extrasystoles, la désaturation en oxygène, les modifications de la tension artérielle et le produit de tension artérielle ont été évalués.

RÉSULTATS : Une augmentation du rythme cardiaque, des modifications du segment ST causées par une ischémie du myocarde, une désaturation en oxygène et des extrasystoles auriculaires et ventriculaires transitoires étaient fréquentes pendant la CPRE par rapport aux occurrences au sein du groupe témoin. Chez un patient, un bloc de branche gauche transitoire s'est développé, attribuable à une hypertension préexistante accompagnée d'une cardiomégalie. Un patient a développé une tachycardie ventriculaire et un autre, une bradycardie sinusale, mais celleci était causée par une maladie du sinus.

CONCLUSIONS : L'ischémie myocardique transitoire et diverses arythmies cardiaques sont fréquentes chez les personnes âgées qui subissent une CPRE. Une surveillance non envahissante pertinente semble justifiée pendant cette intervention.

\footnotetext{
${ }^{1}$ Section of Medical Sciences, School of Health, Patras Highest Institute of Education and Technology, Patras; ${ }^{2}$ Departments of Gastroenterology and Radiology, NIMTS and KAT General Hospitals, Athens; ${ }^{3}$ Department of Cardiology, Ioannina Medical School, Ioannina; ${ }^{4}$ Department of Cardiology, "Agios Andreos" General Hospital, Patras; ${ }^{5}$ Medical Student, Greece

Correspondence and reprints: Professor Nicholas G Kounis, MD, 7 Aratou Street, Queen Olga's Square, Patras 26221, Greece.

Telephone 000302610279549, fax 00302610279579, e-mail ngkounis@otenet.gr
}

Received for publication April 25, 2003. Accepted July 7, 2003 
$\mathrm{M}$ anipulation of various body structures during routine or specific diagnostic and therapeutic techniques have been reported to be associated with cardiac arrhythmias and other cardiorespiratory complications. Such changes have occurred during tracheal suctioning (1), rectal examination (2), distention of the abdominal viscera (3), intravenous urography (4), coronary angiography (5), gastroscopy (6), sigmoidoscopy (7), barium enema (8) or small bowel enema (9). These events may be transient and not hazardous, but in some occasions they have been fatal (10-16). Gastrointestinal endoscopy is a modern and valuable procedure and consistently gives useful diagnostic and therapeutic results. Although cardiac arrhythmias and ST segment depression occur during gastrointestinal endoscopy even in younger patients $(13,14)$, the elderly population is more prone to silent myocardial ischemia which manifests either as electrocardiographic ischemic changes or as disturbances of cardiac rhythm.

We previously have reported electrocardiographic changes in a middle-aged (17) and in elderly (9) populations during small bowel enema. However, there are no reports on any cardiac events during endoscopic retrograde cholangiopancreatography (ERCP) in elderly (greater than 70 years of age) patients, who seem to be more vulnerable to such procedures. Consequently, we have undertaken the following study to determine the incidence of any cardiac arrhythmia, changes in oxygen saturation, heart rate and blood pressure, and to identify those elderly patients at risk during the procedure.

\section{Subjects}

\section{SUBJECTS AND METHODS}

Thirty patients scheduled to undergo ERCP were recruited to the study and were monitored elecrocardiographically with Holter tape recorders. Written informed consent was obtained for data correction and storage on magnetic media. The patients included 18 women and 12 men of mean age 73 years (SD 2, range 71 to 79 years). Their mean weight was $66.5 \mathrm{~kg}$ (SD 18.3, range 44 to 100). All current medications were continued to the time of the procedure. No oxygen was administered in the observation period. Premedication was not given until few minutes before ERCP. Diazepam and Buscopan (Boehringer Ingelheim, Canada) were given for sedation and duodenal relaxation. No opioids were given in the study period. Data were not available to the investigator, the endoscopist or the radiologist during the procedure. The clinical characteristics of the patients are outlined in Table 1.

\section{Methods}

After the usual skin preparation, modified $V_{2}$ and $V_{5}$ electrocardiographic leads were recorded on two channel Circadian Recorders (Circadian Inc, USA). The lead of most significance $\left(\mathrm{V}_{5}\right)$ was analyzed in detail. The positive electrode was placed in the $V_{5}$ position and the negative electrode was placed in the right intraclavicular fossa. Because the procedure was elective, electrocardiographic recording usually was initiated $4 \mathrm{~h}$ before the procedure and was continued during the examination and $4 \mathrm{~h}$ after it. All patients were advised to record in a diary any symptoms of palpitations, shortness of breath or chest pain. Immediately before ERCP, a 12-lead electrocardiogram and resting rhythm strip was available during Valsalva maneuver and during its recovery time. Continuous arterial blood pressure and oximetry monitoring data were recorded throughout the procedure. When it was necessary, arterial blood pressure also was measured by cuff sphygmo-
TABLE 1

Clinical characteristics of $\mathbf{3 0}$ patients undergoing endoscopic retrograde cholangiopancreatography

\begin{tabular}{lc}
\hline Characteristics & $\mathbf{n}(\%)$ \\
\hline Patients & $30(100)$ \\
Mean age (yrs) & $73(\mathrm{SD} 2$, range $71-79$ yrs) \\
Men/Women & $12(40) / 18(60)$ \\
Current medications & \\
Angiotensin converting enzyme ihhibitors & $4(13)$ \\
Angiotensin receptor blockers & $3(10)$ \\
Beta-blockers & $2(6.6)$ \\
Anticoagulants (Warfarin) & $2(6.6)$ \\
Sulfonylureas & $3(10)$ \\
Digoxin & $1(3.3)$ \\
Nitrates & $3(10)$ \\
Hydrochlorothiazide & $1(3.3)$ \\
Hypertension & $8(26.6)$ \\
History of heart failure & $5(16.6)$ \\
Diabetes mellitus & $3(10)$ \\
History of angina on effort & $5(16.6)$ \\
Previous myocardial infraction & $3(10)$ \\
Cardiomegaly on chest x-ray & $3(10)$ \\
Intraventricular septal hypertrophy & $6(20)$ \\
on echocardiogram & \\
\hline
\end{tabular}

*Some patients gave history of more than one condition

manometer in supine position. During analysis the rate-pressure product was calculated by microcomputer for each of one minute recording. Two channel qualitative and quantitative electrocardiographic analysis was performed by a computerized nontriggered template system. Particular attention was paid to arrhythmias of any kind, change in cardiac axis, conduction defects, pauses, ST segment changes and extrasystoles. The following definitions were used. Myocardial ischemia: a depression or elevation in ST segment of $0.1 \mathrm{mV}$ or more from baseline measured at $60 \mathrm{~ms}$ from the j point; episodic hypoxemia: a sudden decrease in oxygen saturation of more than $4 \%$ from baseline (18); tachycardia: a heart rate above 100 beats/min; bradycardia: a heart rate below 50 beats/min; abnormal complexes: abnormal QRS-shaped complexes with a coupling interval of more than $80 \%$ of the preceding RR interval; ventricular extrasystoles: abnormal QRS-shaped complexes with a coupling interval less than $80 \%$ of the preceding RR interval.

\section{Control subjects}

Thirty elderly age- and disease-matched patients not receiving any premedication, served as controls. They were undergoing chest, abdomen, bone or upper gastrointestinal small bowel follow-up studies and they had $8 \mathrm{~h}$ of electrocardiographic monitoring covering the period before, during and after the examination. The clinical characteristics of the control subjects are shown in Table 2.

\section{Statistical analysis}

Absolute differences in the number of arrhythmias, heart rate and oxygen saturation were compared between the hour of the examination and the closest hour when monitoring findings were most reliable, using Wilcoxon's paired t-test (statistical significance at $\mathrm{P}<0.05)$. Differences in the prevalence of arrhythmias and ST segment changes between baseline periods and the procedure were accessed by $\chi^{2}$ test. 
TABLE 2

Clinical characteristics of 30 control subjects

\begin{tabular}{lc}
\hline Characteristics & $\mathbf{n}(\%)$ \\
\hline Patients & $30(100)$ \\
Mean age (years) & 73 (SD 1.5, range $70-80$ yrs) \\
Men/Women & $15(50) / 15(50)$ \\
Radiological procedure & \\
Chest & $10(34)$ \\
Plain abdomen & $7(23)$ \\
Bone & $8(27)$ \\
Barium swallow & $5(16)$ \\
\hline
\end{tabular}

\section{RESULTS}

Heart rate

Twenty nine patients (96\%) had increased heart rate during and immediately after ERCP compared with the rate before the endoscopy $(\mathrm{P}<0.05)$, but the increased heart rate in the two patients receiving therapeutic $\beta$-blockers for ischemic heart disease and in the patient receiving digoxin was not statistically significant. However, the patients who underwent ERCP had a higher mean heart rate $(98.3$ beats/min; $95 \%$ CI 92.1 to 103.3 ), than the control subjects ( 70.1 beats/min; $95 \%$ CI 63.2 to 73.6 ); statistical significance at $\mathrm{P}<0.05$ for patients and control subjects during and after the procedure (Figure 1). In $27(90 \%)$ patients, sinus tachycardia developed with heart rate exceeding 100 beats/min. This tachycardia gradually subsided after the examination. In one $(3 \%)$ patient, sinus bradycardia developed but this patient had suffered a previous myocardial infraction and had been diagnosed to have sick sinus syndrome.

\section{Cardiac rhythm}

The electrocardiograms before the procedure showed no cardiac rhythm disturbances in 20 (67\%) patients. However, two (7\%) patients had pre-existing atrial fibrillation, five (16\%) patients had premature atrial complexes and three (10\%) patients had premature ventricular complexes. During the procedure, premature atrial complexes appeared in 19 (63\%) patients, premature ventricular complexes appeared in nine $(30 \%)$ patients, a burst of supraventricular tachycardia developed in one $(3 \%)$ patient, a short run of ventricular tachycardia appeared in one (3\%) patient and transient left bundle branch block (LBBB) in one $(3 \%)$ patient. The patient with the LBBB was hypertensive, had cardiomegaly in the chest radiograph and developed premature complexes. Significant differences were found upon comparing the absolute number of atrial and ventricular premature complexes during ERCP and the baseline period (Table 3). In comparing the arrhythmias appearing in the control group during chest, bone, abdomen and upper gastrointestinal small bowel follow-through with the baseline period, significant differences were not found. The number of patients in whom premature atrial complexes, sinus tachycardia and premature ventricular complexes developed during ERCP was significantly larger than the control group

The existence of normal or abnormal pre-ERCP electrocardiogram had little prognostic value in predicting the change of electrocardiographic changes developing during the procedure (Table 4). Of the 22 patients who had clinical, radiological and echocardiographic evidence of heart disease, unifocal ventric-

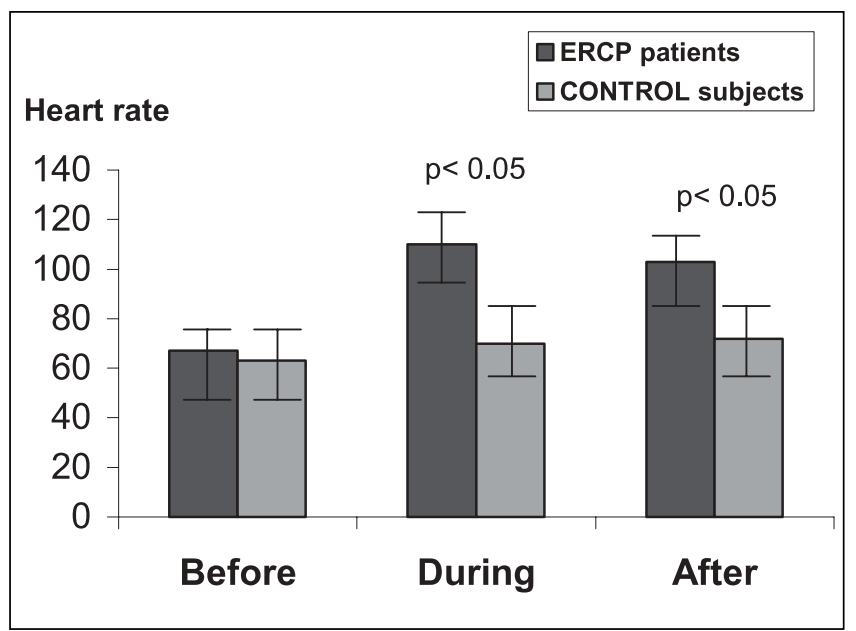

Figure 1) Heart rate (mean value, 95\% CI) before, during and after procedure in 30 elderly patients undergoing ERCP and in 30 age- and disease-matched control patients.

\section{TABLE 3}

Arrhythmias during endoscopic retrograde cholangiopancreatography (ERCP) compared with the baseline period

\begin{tabular}{lccccc}
\hline \multirow{2}{*}{ Arrhythmias } & \multicolumn{2}{c}{ Baseline } & \multicolumn{2}{c}{ ERCP } \\
& $\mathbf{n}(\%)$ & $\mathbf{9 5 \%} \mathbf{~ C l}$ & $\mathbf{n}(\%)$ & $\mathbf{9 5 \%} \mathbf{~ l ~}$ & $\mathbf{P}$ \\
\hline Sinus tachycardia & $0(0)$ & NA & $27(90)$ & $70-96$ & - \\
Sinus bradycardia & $0(0)$ & NA & $1(3.3)$ & $1-22$ & - \\
Premature atrial complexes & $5(16.6)$ & $3-25$ & $19(63.3)$ & $45-95$ & $<0.05$ \\
Supraventricular tachycardia & $0(0)$ & NA & $1(3.3)$ & $1-20$ & - \\
$\begin{array}{l}\text { Premature ventricular } \\
\quad 3(10)\end{array}$ & $3-27$ & $9(10.2)$ & $47-90$ & $<0.05$ \\
complexes & & & & & \\
Ventricular tachycardia & $0(0)$ & NA & $1(3.3)$ & NA & - \\
\hline
\end{tabular}

NA Not applicable

ular extrasystoles developed in eight, multifocal ventricular extrasystoles developed in three, atrial extrasystoles developed in six and sinus tachycardia in 20.

\section{ST segment}

ST segment changes (depression or elevation) during ERCP, in comparison with the baseline electrocardiogram, were considered as sign of myocardial ischemia. Sixteen (53\%) patients developed ST segment changes (15 ST depression and one ST elevation) during the procedure. In all patients the changes were asymptomatic. In all instances the ST segment changes disappeared when the endoscope was withdrawn. There were no significant ST segment changes in the control group during chest, bone, abdomen and small bowel through studies.

\section{Laboratory}

In all patients oxygen saturation decreased during ERCP from a mean baseline $91.4 \%$ to a minimum of $78.6 \% \quad(\mathrm{P}<0.05)$. Saturation recovered to the baseline level $30 \mathrm{~min}$ after the study. Linear regression analysis was performed for arterial oxygen saturation and ST segment in 16 patients. A significant correlation was found between oxygen saturation and ST segment changes (Figure 2) 
TABLE 4

Prevalences of PACs, ST, and PVCs during Holter monitoring of patients with ERCP and in control subjects

\begin{tabular}{lccc}
\hline & $\begin{array}{c}\text { Control } \\
\text { Subjects }(\mathbf{n})\end{array}$ & $\begin{array}{c}\text { ERCP } \\
\text { Patients }(\mathbf{n})\end{array}$ & $\mathbf{P}$ \\
\hline PACs & 5 & 19 & $<0.05$ \\
ST & 0 & 27 & $<0.05$ \\
PVCs & 3 & 9 & $<0.05$
\end{tabular}

ERCP Endoscopic retrograde cholangiopancreatography; PACs Premature atrial complexes; PVCs Premature ventricular complexes; ST Sinus tachycardia;

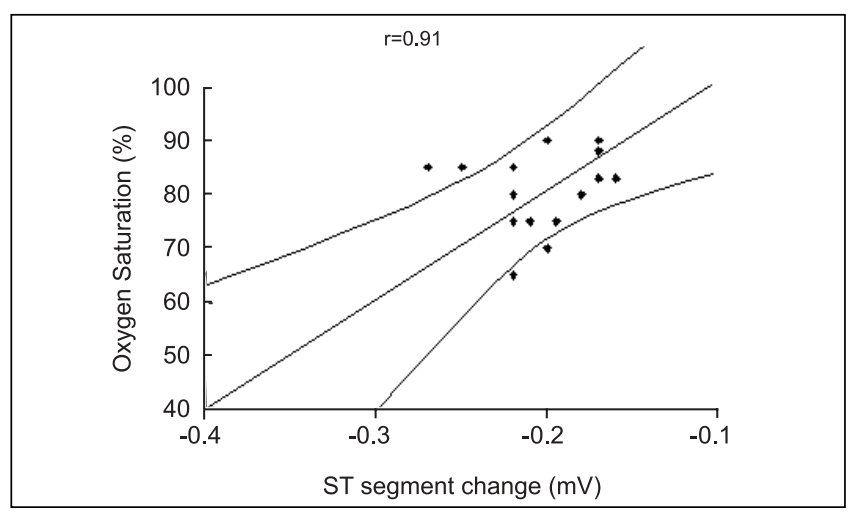

Figure 2) Linear regression shown significant correlation between oxygen saturation and ST segment depression. 95\% confidence lines

\section{DISCUSSION}

The present study shows that arrhythmias of all kinds, conduction disturbances, electrocardiographic changes compatible with myocardial ischemia and oxygen desaturation are encountered in elderly patients undergoing ERCP. There are previous studies (18-20) using hemodynamic monitoring (heart rate, blood pressure, rate pressure product), pulse oxymetry and electrocardiographic monitoring during gastrointestinal endoscopic procedures which associate cardiac risk with changes observed in heart rate, asymptomatic arrhythmias, ST segment changes, oxygen desaturation and changes in blood pressure. Some studies $(21,22)$ have suggested that patients with heart disease were at an increased risk during the above procedures. In one study (19) including 52 consecutive patients undergoing upper gastrointestinal endoscopy, arrhythmias during the procedure were common and tended to occur more frequently in the elderly and in persons with heart disease and chronic lung disease. In another study (23) patients with cardiac history, before esophageal dilation, were particularly prone to cardiorespiratory events. It was found that $90 \%$ of patients with pre-existing cardiac disease developed an event during the procedure.

Other studies (24-26) have shown that patients with increased age are particularly prone to low oxygen saturation, pain during the procedure and increased duration of the procedure.

The current study suggests also that electrocardiographic and laboratory changes during ERCP are frequent, especially in elderly patients with coexisting cardiac disease. These changes, however, seem to be asymptomatic. The abnormalities observed ranged from sinus tachycardia to innocent and transient atrial and ventricular premature beats as well as ST segment changes and oxygen desaturation. In one patient asymptomatic supraventricular tachycardia and in another patient a burst of ventricular tachycardia developed but these two patients had ischemic heart disease. The patient who developed sinus bradycardia during ERCP had suffered a previous myocardial infraction and had been diagnosed as having sick sinus syndrome. All patients had diminished blood oxygen saturation and 16 developed ST segment changes compatible with ischemic heart disease.

The mechanisms by which the cardiorespiratory and electrocardiographic changes occur during ERCP remain speculative. During upper gastrointestinal endoscopy airway obstruction (24), gastric or salivary aspiration, direct pressure on the diaphragm (26), air insufflation (22) and stress and anxiety triggering catecholamine release may contribute $(9,22,27,28)$. During ERCP several factors tend to increase sympathetic activity. Neural impulses from higher centers in the brain may be transient risk factors (29). The distension and collapse of hollow abdominal viscera during the procedure might be another factor accounting for the electrocardiographic abnormalities (19). Indeed, ERCP is a method with many applications especially for patients suspected to have billiary and pancreatic problems. However, it involves the insertion of a side-viewing duodenoscope through the oesophagus to the stomach, pylorus, duodenal pulb and papilla. This cannulation involves special manipulations, angulations, air insufflation and sometimes becomes unpleasant to the patient. It has been suggested that the removal of the insufflated air before the removal of the endoscope may lower the risk of cardiovascular problems (19). The use of a narrow diameter endoscope has been suggested to cause less hypoxia than the standard diameter endoscope $(30,31)$. The increased load of the endoscopic examination on the cardiovascular function may be caused by psychological stress before and during examination (32) as well as by the physical effects of the anticholinergic drugs (33). Indeed, all of our patients were receiving, as premedication, diazepam and Buscopan.

Buscopan increases heart rate because it has anticholinergic properties. Premedication with anticholinergic drugs tends to shift the balance of the autonomous nervous system towards sympathetic dominance which increases the cardiac work and heart rate. It has been suggested that patients with cardiac disease, anticholinergic drugs may increase the risk of cardiac complications during endoscopic examination and they should be avoided in shuch patients (33). These authors state that withholding anticholinergic premedication does not seriously affect the endoscopic examination (33). To confirm whether psychological stress could alter the cardiac vulnerability, the investigators (33) compared the heart rate in patients who had never undergone endoscopy with those who had. They found that the heart rate increased during endoscopy, but did not increased significantly in those who had previous endoscopy, indicating that psychological factors play an important role in the electrocardiographic changes during endoscopy. Neural inhibition of the diaphragm by viscerosomatic reflexes due to esophageal and gastric distention has been thought to be another possibility (34-36). Additionally an increase in vagal activity as a result of gastrointestinal manipulation may induce vasospasm and reduce coronary blood flow with consequent brochospasm, ventilation-perfusion mismatch, hypoxia and blood desaturation (36). These effects may be potentiated by benzodiazepines given as premedication sedatives (37). However endoscopy without sedation also causes significant 
reduction in oxygen saturation after introduction of the endoscope $(38,39)$.

The present study is the only one in the literature to monitor elderly patients, greater than 70 years of age during ERCP. Elderly patients might be more vulnerable to hypoxemia. Hypoxaemia is a documented consequence (40) of endoscopic manipulations and has been attributed to hypoventilation secondary to sedative medication, partial obstruction by the endoscopy and possible ventilation-perfusion mismatch caused by autonomic disturbance. In all our patients the oxygen saturation decreased during the procedure and this was correlated with ST segment deviation and arrhythmias. Twenty nine of our patients (96\%) developed also sinus tachycardia with heart rate above 100 beats/min. However, while all of our patients developed hypoxaemia and 29 sinus tachycardia, only 16 patients developed ST segment changes. Therefore, it seems that the ST segment changes of the 16 patients were related to both hypoxaemia and sinus tachycardia. It has been suggested 41 that the development of myocardial ischemia during ERCP, manifesting an ST segment deviation, is related to increase cardiac oxygen demand caused by tachycardia rather than decreased oxygen supply caused by hypoxaemia. Our data cannot support this suggestion. We did not use beta-blockade in order to reduce the tachycardia in our patients because this was

\section{REFERENCES}

1. Shim C. Fine N, Fernandez R, Williams MB. Cardiac arrhythmias resulting from tracheal suctioning. Ann Intern Med 1969;71:1149-53.

2. Earnest DL, Fretcher GF. Danger of rectal examination in the patients with acute myocardial infraction: Fact or fiction? N Engl J Med 1969;281:238-41.

3. Skjennald A, Samset JH, Duodeno-jejunal intubation in the examination of the small intestine. Clin Radiol 1980;31:221-4

4. Stadelnik R, Davies R, Vera Z. Hilliard G, DaSilva O. Ventricular tachycardia during intravenus urography. JAMA 1974;229:686-7.

5. Coskey RL, Magidson O. Electrocardiographic response to selective coronary arteriography. Br Heart J 1967;29:512-9.

6. Schuman BM, Gale H. Electrocardiographic changes associated with gastroscopy. Bull Gastroint Endosc 1969;8:10-3.

7. Fletcher RL, Earnest DL, Shuford WF. Elecrtocardiographic changes during routine sigmoidoscopy. Arch Intern Med 1968;122:483-6.

8. Higgins CB, Roeske WR, Karniner JS, O'Rourke R, Berk RN. Predictive factors and mechanism of arrhythmias and myocardial ischemic changes in elderly patients during barium enema. $\mathrm{Br} \mathrm{J}$ Radiol 1976;49:1023-7.

9. Zavras GM, Papadaki PJ, Kounis NG, et al. Electrocardiographic changes in elderly patients during small bowel enema. Invest Radiol 1996;5:256-60.

10. Katz D, Selesnick S. Cardiac arrest during gastroscopy. Gastroenterology 1967;33:650-4

11. Palmer ED, Wirts CW. Survey of gastroscopic and esophagoscopic accidents. JAMA 1957;164:2012-5.

12. Daneshmend TK, Bell GD, Logan RFA. Sedation for upper gastrointestinal endoscopy: relults of a nationwide survey. Gut 1991;32:12-5.

13. Arrowsmith JB, Gartsman B, Fleisher DE, Benjamin SB. Results of the American Society for Gatsrointestinal endoscopy. U.S. Food and Drug Administration collaborative study on complication rates and drug use during gastrointestinal endoscopy. Gastrointest Endosc 1991;37:421-7.

14. Okazaki Y, Takemoto T. [A report of a case of cardiac arrest soon after gastroscopic examination.] Gastroenterol Endosc 1977;19:123-9 (Japanese).

15. Blakeborough A, Sheridan MB, Chapman AH. Complications of barium enema examinations: A survey of UK Consultant Radiologists 1992 to 1994. Clin Radiol 1997;52:142-8.

16. Yantis PL. Lavage-induced cardiac asystole. Gastrointest Endosc 1984; 30:17. (Lett) not the aim of this study. Beta-blockers reduce heart rate, increase cardiac diastolic filling and improve blood oxygen supply to myocardium. Therefore, beta-blockers have been used to prevent tachycardia during endoscopy. Metoprolol is a beta-blocker which has been used in a double blind randomized controlled trial during ERCP (41) in peripheral vascular surgery (42) and after cardiac operations (43), with positive effect on myocardial oxygen supply and incidence of myocardial ischemia. Beta-blockers have also a strong anxiolytic effect comparable with benzodiazepimes but without concurrent sedation (44).

\section{CONCLUSIONS}

We believe that the encountered electrocardiographic abnormalities and myocardial ischemia during ERCP in elderly patients, are common and usually transient. Clinical evidence of prior heart disease seems to be predisposing factor for these abnormalities. The procedure requires careful evaluation of the risks especially in the elderly people with preexisting cardiac disease. A careful history especially of the cardiovascular system should be obtained in all patients. Non invasive monitoring during the procedure and appropriate clinical observation by the cardiologist, endoscopist and radiologist will result in safer examination and seems to be justified.

17. Kelekis D, Papadaki PJ, Zavras GM, Kounis NG, Vassiliou P, Fezoulidis IB. EKG-Veranderungen wahrend der Enteroklyse. Rontgenpraxis 1993;46:108-10.

18. Tremper KK, Barker SJ. Pulse oximetry. Anesthesiology 1989;70:98-108.

19. Mathew PK, Ona FV, Damecski K, Wallance WA. Arrhythmias during upper gastrointestinal endoscopy. Angiology 1979;11:834-40.

20. Wilcox CM, Faibicher M, Wenger NK. Prevalence of silent myocardial ischemia and arrhythmias in patients with coronary heart disease undergoing gastrointestinal tract endoscopic procedures. Arch Intern Med 1993;153:2325-30.

21. Murray AW, Morran CG, Kenny G, Macfarlane P, Anderson JR. Examination of cardiorespiratory changes during upper gastrointestinal endoscopy. Anaesthesia 1991;46:181-4.

22. Steffes CP, Sugawa C, Wilson RF, Hayward SR. Oxygen saturation monitoring during endoscopy. Surg Endosc 1990;4:175-8.

23. Thompson AM, Park KGM, Kerr F, Munro A. Safety of fibreoptic endoscopy: Analysis of cardiorespiratory events. Br J Surg 1992;79:1046-9.

24. Barkin JS, Krieger B, Blinder M, Bosch-Blinder L, Goldberg RI, Phillips RS. Oxygen desaturation and changes in breathing pattern in patients undergoing colonoscopoy and gastroscopy. Gastrointest Endosc 1989;35:526-30.

25. Dark DS, Campbell DR, Wesselius LJ. Arterial oxygen desaturation during gastrointestinal endoscopy. Am J Gastrenterol 1990;85:1317-21.

26. Patel NM. Paroxysmal ventricular complexes during coloscopy. Gastrointest Endosc 1986;32:234.

27. Marsh WH, Bronner MH, Yantis PL, Kilgore JW, Rickoff MI. Ventricular ectopy associated with peroral colonic lavage. Gastrointest Endosc 1986;32:259-63.

28. Lown B, Verner RL. Neuroactivity and nentricular fibrillation. N Engl J Med 1976;294:1165-70.

29. Hoffman BF. Autonomic control of cardiac rhythm. Bull N Y Acad Med 1967;43:1087-96.

30. Rozen P, Fireman Z, Gilat T. Arterial oxygen tension changes in elderly patients undregoing upper gastrointestinal endoscopy II. Influence of the narcotic premetication and endoscope diameter. Scand J Gastroenterol 1981;16:299-303.

31. Rozen P, Fireman Z, Gilat T. The causes of hypoxemia in elderly patients during endoscopy. Gastrointest Endosc 1982;28:243-6.

32. Davidson T, Levine M, Meyerowitz R. Ventricular fibrilation during 
colonoscopy: Case report and review of the literature. Am J Gastroenterol 1985;80:690-3.

33. Segawa K, Nakazawa S, Yamao K, et al. Cardiac response to upper gastrointestinal endoscopy. Am J Gastrenterol 1989;84:13-6.

34. Rosenberg J, Hansen BJ. Possible role of autonomic afferents in treatment of postoperative hiccups. Lancet 1989;2:873.

35. De Troyer A, Rosso J. Reflex inhibition, of the diaphragm by esophageal afferents. Neurosci Lett 1982;30:43-6.

36. Vawter M, Rutz R, Alaama A, Aronow WS, Dagradi AE.

Electrocardiographic monitoring during colonoscopy. Am J Gastroetnterol 1974;63:155-7.

37. Macrae FA, Tank G, Williams CB. Toward safer colonoscopy: A report on the complications of 5000 diagnostic or therapeutic colonoscopies. Gut 1983;24:376-83.

38. Pecora AA, Chiesa JC, Alloy AM, Santoro J, Lazarus B. The effect of upper gastrointestinal andoscopy on arterial $\mathrm{O}_{2}$ tension in smokers and nonsmokers with and without premedication. Gastronintest Endosc 1984;30:284-8.

39. Whorwell PJ, Smith CL, Foster KJ. Arterial blood gas tensions during upper gastrointestinal andoscopy. Gut 1976;17:797-800.

40. Rosenberg J, Jorgensen CN, Rasmussen V, Vibits H, Hansen PE. Hypoxaemia and myocardium ischaemia during and after endoscopic cholangiopancreatography: Call for further papers. Scand J Gastroenterol 1992;27:717-20.

41. Rosenberg J, Overgaard H, Andersen M, Rasmussen V, Schultze S. Double blind randomized controlled trial of effect of metoprolol on cholangiopancreatography. Br Med J 1996;313:258-61.

42. Pasternak PF, Grossi EA, Baumann FG, Riles TS, Lamparello PJ, Giagnola G. Beta blockade to decrease silent myocardial ishcemia during peripheral vascular surgery. Am J Surg 1989;158:113-6.

43. Wesslen O, Hallhagen S, Ekroch R, Jangerbung R, Joachimsson PO, Nordgren L. High-dose intravenous $\beta$-blockade in patients early after cardiac operations: Negative inotropism versus myocardial oxygen economy. J Thorac Cardiovasc Surg 1992;104:1672-8.

44. Jakobsen CJ, Blom L, Brondbjerg M, Lenler-Petersen P. Effect of metoprolol and diazepam on pre-operative anxiety. Anaesthesia 1990;45:40-3. 


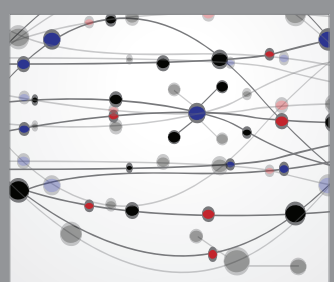

The Scientific World Journal
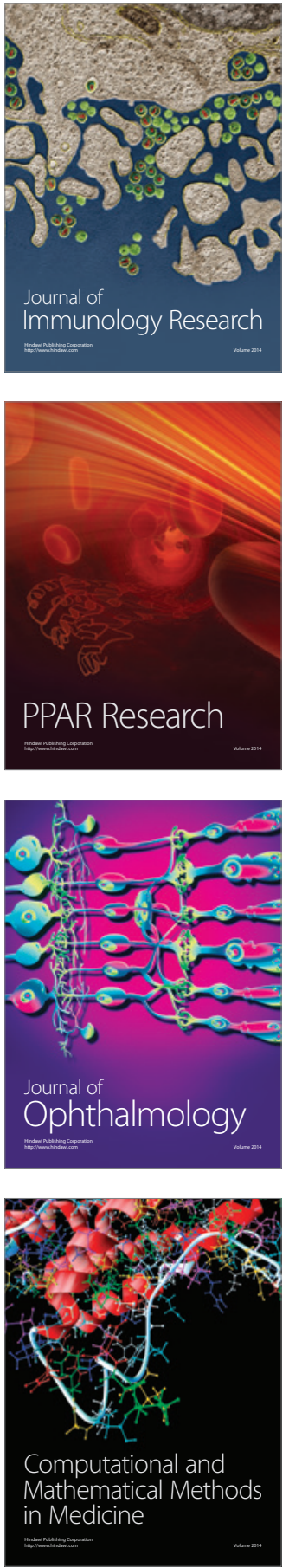

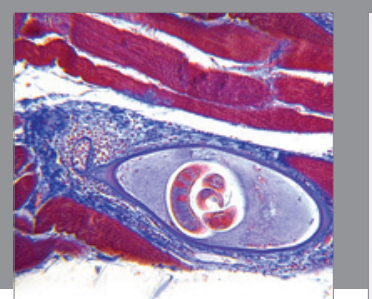

Gastroenterology Research and Practice

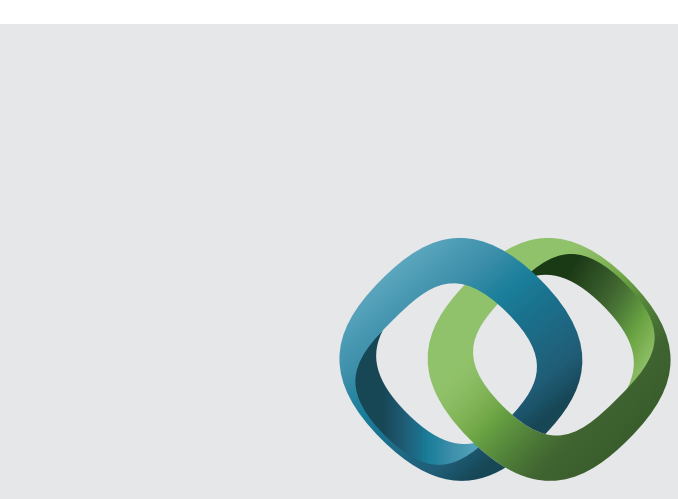

\section{Hindawi}

Submit your manuscripts at

http://www.hindawi.com
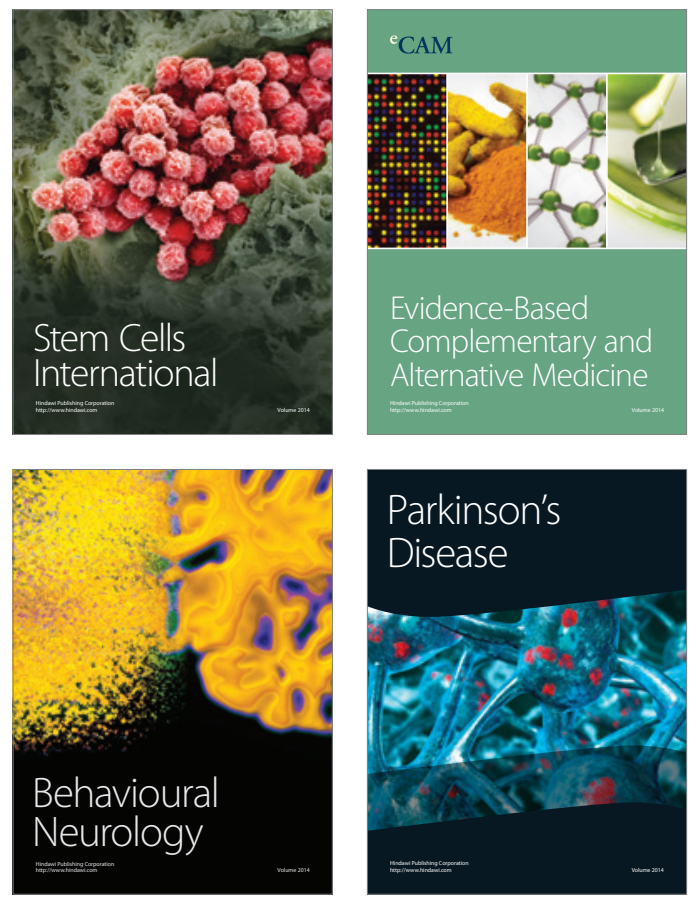
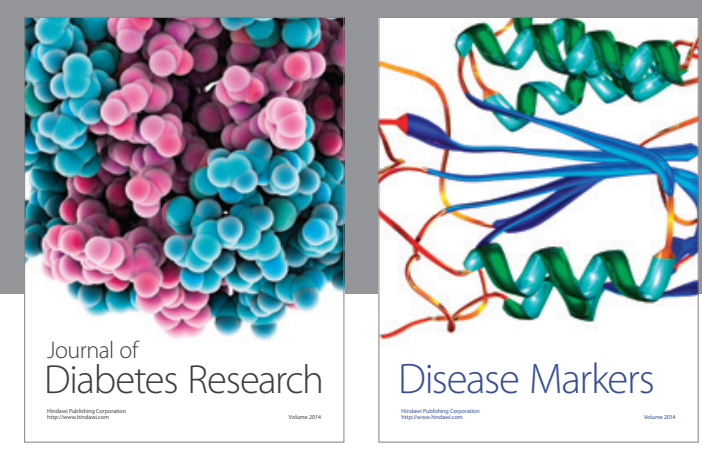

Disease Markers
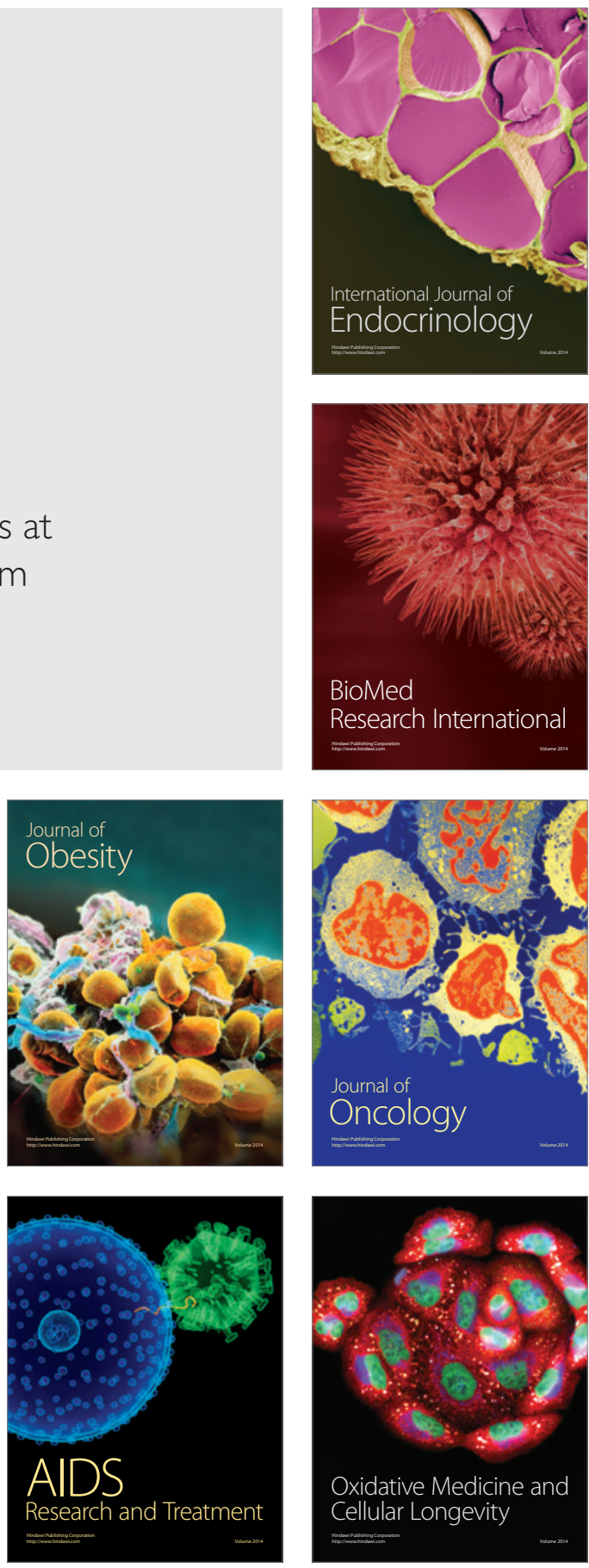